\title{
A CIÊNCIA DO DIREITO NA CONCEPÇÃO DE GEORG FRIEDRICH PUCHTA ${ }^{1}$
}

\author{
Albenir Itaboraí Querubini Gonçalves ${ }^{2}$
}

RES UMO: O presente trabalho analis a compreensão do jurista alemão Georg Friederich Puchta sobre a Ciência do Direito e seus principais temas.

PALAVRAS-ChAVE: Ciência do Direito. Escola Histórica do Direito. Metodologia do Dire ito. Fontes do Direito.

\section{Juris prudence in Georg Friederich Puchta's thought}

ABSTRACT: The present essay examines the German jurist Georg Friederich Puchta's understanding of Jurisprudence and its main themes.

KEY WORDS: Jurisprudence. German Historical School of Law. Methodology of Law. Sources of Law.

SUMÁRIO: 1 Introdução. 2 Breves apontamentos sobre a vida e a obra de Puchta. 3 Ideias iniciais: Ciência do Direito, diferenças e relações entre a Filosofia do Direito e a Jurisprudência, sistema e História do Direito, objeto da Ciência do Direito. 4 Sobre o desenvolvimento da ideia do Direito na história. 5 Sobre a origem e fontes do Direito, o Dire ito Consuetudinário, o Dire ito Leg is lativo, o Dire ito Científico, os modos de reconhecer o Direito e a sua mutação. 6 Considerações finais. 7 Referências bibliográficas.

"A vida no tempo é um perene movimento, uma ininterrupta sucessão". (Puchta)

\section{INTRODUÇÃO}

O presente trabalho tem por finalidade realizar uma análise sobre a ideia e compreensão da Ciência do Direito (ou Jurisprudência) segundo a concepção desenvolvida pelo jurista alemão Georg Friedrich Puchta, que foi integrante da chamada Escola Histórica do Direito ${ }^{3}$, além de ser considerado o principal discípulo de Friedrich Carl von Savigny (1772-1840).

\footnotetext{
${ }^{1}$ O presente texto foi elaborado com base em apresentação realizada no Seminário apresentado no dia 19 de outubro de 2009, na Disciplina "Temas de História do Direito: II - Codificação e Ciência Jurídica no Séc. XIX”, min is trada pelo Prof. Dr. Alfredo de J. Flores, no Programa de Pós-Graduação em Direito da Universidade Federal do Rio Grande do Sul (PPGDir - UFRGS), cujo tema fo i "Puchta e a Ciência das Pandectas". Artigo elaborado em 30 de outubro de 2009.

2 Bacharel em Ciências Jurídicas e Sociais pela Universidade Federal de Santa Maria - UFSM. Especialista e Mestrando em Dire ito pela Universidade Federal do Rio Grande do Sul - UFRGS. E-mail: albenir@gmail.com.

${ }^{3}$ A Escola Histórica do Direito designa o movimento cultural, na esfera da Ciência do Direito, surgido na Alemanha entre o final do Século XVIII e início do Século XIX. O referido movimento destacava-se pela importância dada à História (tradição jurídica) no estudo dos fatos jurídicos e sociais, tendo sido responsável por uma apurada reconstrução do direito romano justinianeu. A paternidade da Escola
} 
Infelizmente, as obras de Puchta não foram objeto de traduções para outros idiomas, tais como para o idioma português ou espanhol, fato que explica o atual desconhecimento das suas idéias na América Latina. Além disso, o pouco que se conhece sobre Puchta decorre de sínteses elaboradas a partir da obra de alguns comentadores (a exemplo de Karl Larenz, Franz Wieacker e Walter Wilhelm, que o denominam como fundador da chamada "jurisprudência dos conceitos"4), cujas abordagens nem sempre correspondem fidedignamente às ideias constantes nas obras originais ou, em algumas vezes, chegam até mesmo a distorcer o seu conteúdo, a fim de justificarem suas teses, a exemplo da vulgarização de ter sido Puchta e os demais integrantes da Escola Histórica do Direito tidos como predecessores do positivismo jurídico.

É por tal razão, buscando contribuir com o debate acadêmico, que o presente trabalho se propõe a realizar uma breve análise e resgate da concepção de Puchta sobre a Ciência do Direito, tomando-se por base as ideias desenvolvidas no Livro I (Introdução) da sua obra "Kursus der Institutionen" ${ }^{5}$, na qual ele aborda os seguintes temas: Capítulo I - Ciência do Direito, diferenças e relações entre a Filosofia do Direito e a Jurisprudência, Sistema e História do Direito, objeto da Ciência do Direito; Capítulo II - desenvolvimento da ideia do Direito na história; Capítulo III - origem externa do Direito, fontes particulares do Direito, Direito Consuetudinário, Direito Legislativo, Direito Científico, modos de reconhecer o Direito e mutação do Direito.

Histórica é atribuída a Gustav Hugo (1764-1844) pelo próprio Friedrich Carl von Savigny, que foi o seu principal representante. Além de Hugo e Savigny, o outro grande representante da Escola Histórica foi Puchta. Um dos marcos da Escola Histórica do Direito foi a publicação da obra "Vom Beruf unserer Zeit für Gesetzgebung und Rechtswissenschaft" ("Da Vocação de Nossa Época para a Legis lação e a Ciência do Direito"), publicada em 1814 por Savigny em resposta à obra "Über die Nothwendigkeit eines allgemeinen bürgerlichen Rechts für Deutschland" ("Sobre a Necessidade de um Dire ito Civil Geral para a Alemanha"), publicada no mes mo ano por Anton Friedrich Justus Thibaut (1772-1840). Sobre a Escola Histórica do Direito, vide: WIEACKER, Franz. História do Direito Privado Moderno. 3. ed., trad. portuguesa de A. M. Botelho Hespana, Lisboa: Fundação Calouste Gulbenkian, 2004, p. 397 e seguintes. PARESCE, En rico. "Scuola Storica del Diritto", in: Novissimo Digesto Italiano. $3^{\mathrm{a}}$ ed. a cura di Antonio Azara e Ernesto Eula. Tomo XVI. Torino: Unione Tipografico-Editrice Torinese, 1957, pp. 823827. Sobre a polêmica da codificação travada entre Savigny e Thibaut: THIBAUT, Anton F. J.; SA VIGNY, Friedrich C. von. La Codificación: una controvérsia programática basada em sus obras "Sobre la necesidad de um Derecho civil general para Aleman ia" y "De la vocacion de nuestra época para la legislación y la ciência del Derecho". Introdução e compilação de Jacques Stern. Tradução de José Dias Garcia. Madrid: Aguilar, 1970.

${ }^{4}$ Sobre o assunto: LARENZ, Karl. Metodologia de la Ciencia del Derecho. Tradução de Marcelino Rodríguez Molinero. Barcelona: Ariel, 1994. W ILHELM, Walter. La Metodologia Jurídica en el Siglo XIX. Tradução de Rolf Bethmann. Madrid: EDERSA, 1980. WIEACKER, Franz. História do Direito Privado Moderno. Op.cit.

${ }^{5}$ O presente foi elaborado com base na versão italiana: PUCHTA, G. F. Corso delle Istituzioni. Tradotto e preceduto da un discorso da A. Turchiarulo. Prima Edizione, Vol. I. Napoli: Tipografia All'Insegna del Diogene, 1854. 
Inicialmente, realizar-se-á uma breve referência à biografia de Puchta, passandose diretamente à análise das ideias desenvolvidas por ele na referida obra "Kursus der Institutionen" (expostas no parágrafo anterior) a respeito da Ciência do Direito e seus temas correlatos.

\section{BREVES APONTAMENTOS SOBRE A VIDA E A OBRA DE PUCHTA ${ }^{6}$}

Georg Friedrich Puchta nasceu em 31 de agosto de 1798 em Kadolzburg, na Bavária. Era filho de Wolfgang Heinrich Puchta (1769-1845), conhecido juiz de Ansbach e autor de diversas obras acadêmicas.

Entre 1811-1816 cursou o "gymnasium" em Nuremberg, sob influência de Hegel.

Puchta iniciou em 1816 o Curso de Direito na Universidade de Erlangen, onde lecionava a época o famoso professor Christian Friedrich von Glück (1755-1831). Foi em Erlanger Puchta recebeu as influências das obras de Savigny e do historiador e político Barthold Georg Niebuhr (1776-1831).

Depois de formado, Puchta foi professor em Erlangen (Direito Privado, 1820), München (Direito Romano, 1828), Marburg (Direito Romano e Eclesiástico, 1835), Leipzig (1837) e Berlim (1842), onde sucedeu a Cátedra de Savigny, quando este se afastou da docência para assumir o cargo de Ministro de Estado, fato que demonstra a notável importância e o reconhecimento jurídico de Puchta.

Em 1845 passou a fazer parte do Conselho de Estado ("Staatsrat") e da Comissão Legislativa (“Gesetzgebungskommission”). Puchta veio a falecer, precocemente, em 8 de janeiro de 1846, em Berlim, aos 47 anos.

Puchta foi autor das seguintes obras jurídicas: "Lehrbuch der Pandekten" ("Manual das Pandectas", 1838), "Kursus der Institutionen" (“Curso das Instituições”, 1841-1847), "Das Gewohnheitsrecht" ("Direito Consuetudinário", 1828-1837), "Einleitung in as Recht der Kirche" ("Introdução ao Direito Eclesiástico", 1840) e "Kleine Civilistische Schriften" ("Pequenos Escritos de Direito Civil", 1851 - que se trata de uma coletânea de ensaios editada por Adolph August Friedrich Rudorff).

\footnotetext{
${ }^{6}$ Confira: WIEA CKER, Fran z. História do Direito Pri vado Moderno. 3. ed., trad. portuguesa de A. M. Botelho Hespana, Lisboa: Fundação Calouste Gulbenkian, 2004, p. 455 e seguintes. "PUCHTA GEORG FRIEDRICH". Novissimo Digesto Italiano. $3^{\mathrm{a}}$ ed. a cura di Antonio Azara e Ernesto Eula. Tomo XIV. Torino: Unione Tipografico-Ed itrice Torinese, 1957, p. 586.
} 


\section{IDEIAS INICIAIS: CIÊNCIA DO DIREITO, DIFERENÇAS E RELAÇÕES ENTRE A FILOSOFIA DO DIREITO E A JURISPRUDÊNCIA, SISTEMA E HISTÓRIA DO DIREITO, OBJETO D A CIÊNCIA DO DIREITO}

Em seu "Kursus der Institutionen", Puchta inicia sua abordagem dinâmica a partir de uma linguagem emprestada das ciências naturais. Ele dá início à construção de seu raciocínio com base na ideia de que cada organismo vivo apresenta-se sob um duplo aspecto, da seguinte forma: (a) sob movimento e varied ade em si próprio, consistindo de membros diferentes entre eles, porém conexos e informados (organizados) por uma unidade; e (b) sob uma relação com uma esfera superior, na qual se move e da qual é um dos elementos (p. 1a). É o que acontece, por exemplo, com o Planeta Terra, em suas órbitas de rotação e translação.

Segundo Puchta, essas relações também se manifestam no Direito (que para ele é fato histórico e, consequentemente, é imaginado como um organismo social vivo). No presente caso, esses distintos movimentos tornam o Direito ao mesmo tempo o objeto de uma ciência especial, a chamada Jurisprudência (que caracteriza o movimento em torno do seu próprio eixo - cujo eixo de rotação parece-nos ser os fatos sociais e a prática jurídica), e, dentro de uma abordagem mais geral, também como um elemento, ao considerar-se a Filosofia do Direito (que caracterizaria o movimento de translação do Direito). A partir do referido raciocínio, temos:

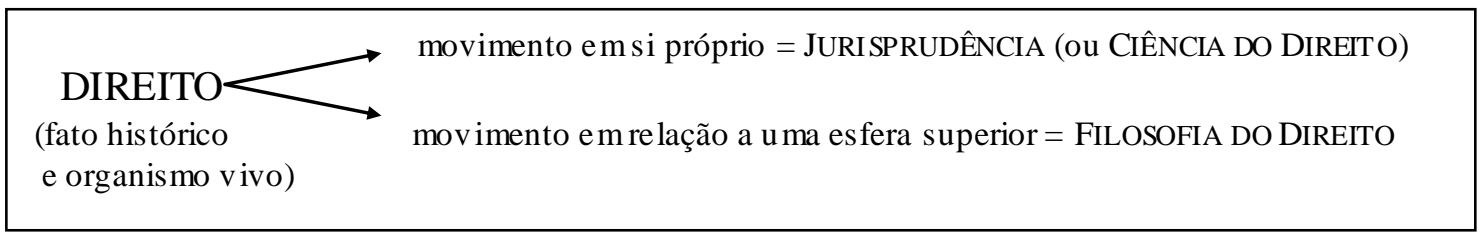

A partir de então, Puchta passa a fazer uma distinção entre a Ciência Positiva do Direito e a Filosofia do Direito. Segundo ele, apenas a Ciência Positiva do Direito possui em seu objeto um direito real positivo e his tórico. Enquanto que, para a Filosofia do Direito (em especial ao tratamento dado pelos filósofos de sua época) nada havia de tradicional, sendo imediatamente trazid a e deduzida pelos postulados da razão universal, alheia por completo da História, emanando invariavelmente das leis da imutável razão e desejando-se denominar um chamado Direito natural ou racional.

Em sua abordagem, Puchta realiza severas críticas à visão racionalista da Filosofia do Direito, ao dizer que ela não possui o verdadeiro Direito em seu objeto e 
também não pode ser considerada como uma verdadeira Filosofia, justamente pela sua falta de vínculo com a História (leia-se também tradição). Sintetiza Puchta que a diferença existente na compreensão da sua época poderia assim ser resumida: " $a$ Ciência Positiva do Direito ocupa-se daquilo que historicamente existe, enquanto que a Ciência Filosófica do Direito daquilo que deveria ser" (p. 1b). Importante destacar, desde já, que Puchta demonstra uma constante preocupação de demonstrar que a teoria somente possui sentido se correlacionada com a prática, evidenciando uma postura ligada à realidade e à História ${ }^{7}$.

Segundo Puchta, o verdadeiro objeto da Filosofia do Direito é o de considerá-lo como membro de um organismo mais vasto, sendo seu ofício demonstrar como esse membro do organismo histórico desenvolve-se por completo, comunicando-se com a Jurisprudência (pp. 1b-2a). Para Puchta, o verdadeiro filósofo pode ser comparado a um vidente: ele penetra no passado, naquilo que passou despercebido pelo historiador, olha para o futuro, que é obscuro para os outros, e, a partir daquilo que entrevê, concebe pensamentos mais elevados (p. 2a). De tal maneira, "abre-se à Filosofia do Direito o campo circunscrito pela realidade, na qual ela experimenta suas forças ao invés de ocupar-se ao seu objeto do estudo do inexistente". Segundo Puchta, "é uma violenta usurpação feita à Filosofia do Direito aquela de subtrair do seu domínio o elemento positivo" (p. 2a).

Já o objeto da Jurisprudência, entendida por Puchta como uma ciência especial, "é o Direito considerado em si próprio e abstratamente da sua qualidade de membro de todo o organismo" (p. 2a). Segundo Puchta, "se, de uma parte, esconde-se do jurista a conexão do Direito como espírito geral da humanidade, e se para alcançá-la lhe é difícil voltar-se a uma ciência mais vasta; da outra parte, lhe é aberta toda a riqueza íntima do direito, as suas divisões internas, cuja consciência será comunicada por ele ao filósofo" (p. 2b).

Por decorrência, é papel do jurista considerar o Direito no seu isolamento e de acordo com a forma com que se apresenta, considerando o dado momento da realidade deste ou daquele povo. Enquanto isso, ao contrário do jurista, é função do filósofo conceber o Direito dos diversos povos apenas como momentos e testemunhos da

\footnotetext{
${ }^{7}$ Conforme consta no texto da versão italiana: "Il dritto como membro dell'intero organismo à pure in questo e con questo la sua storia. Questa storia del dritto consideratto in quella generale delle spiritu dell'umanità è perciò un secondo elemento di considerazione per la filosofia. La filosofia del dritto dee investigare la genesi e lo sviluppo fino all'ultima attuazione nella storia dell 'umanità". (p. 2a)
} 
existência que o direito adquire na História da humanidade, assim como conceber em quais momentos se apresenta de forma isolada ao jurista, conectando-lhes apenas quando um Direito se transforme em outro. Ressalta Puchta, que é essa conexão parcial e externa que é objeto da investigação jurídica, e não aquela geral, na qual os Direitos dos diversos povos adquirem forma apenas nos momentos de uma única e mesma sucessão.

Para Puchta, o Direito como elemento que dá forma ao organismo vivo possui: (a) uma variedade simultânea - enquanto ele é dividido em tantas partes orgânicas que se supõem e compõem reciprocamente; (b) uma variedade sucessiva - estando sujeito a mudanças, seja no seu conjunto ou em suas partes.

Puchta compreende que a Ciência do Direito possui dois lados: (a) um sistemático e outro (b) histórico, sendo que é no consentimento encarregado por eles que consiste a verdadeira Ciência do Direito, ou seja, a verdadeira Ciência do Direito é fruto do somatório de uma visão sistemática e histórica sobre os fenômenos jurídicos. Desta forma, a consciência sistemática do Direito "é aquela que percebe a íntima ligação que lhes une às partes individuais, compreendendo as particularidades como membro do todo, como um corpo que se desenvolve em órgãos especiais" (p. 3a). No entendimento de Puchta, "apenas a concepção sistemática é capaz de dar deduções completas e certas sobre conexões de mais direitos em uma mesma relação jurídica, sobre o poder que exerce um sobre o outro, ou sobre as modificações que sofrem um referido poder recíproco" (p. 3a).

Já a História do Direito, como representação da variedade sucessiva desse organismo vivo, possui uma dupla tendência. "O organismo desenvolve e se modifica tanto no seu conjunto quanto em suas partes, embora cada uma dessas possua uma vida própria, e embora indivisível e essencialmente conexa como o todo, possui mesmo uma história própria, que se desenvolve, porém, naquela mais geral do Direito" (p. 3b). Puchta diz ser necessário distinguir duas partes na História do Direito: (a) aquela do direito em geral (História externa) e (b) a história dos elementos especiais deste (História interna - representada pela antiguidade jurídica, a exemplo da filologia).

O objeto da História externa (Direito em geral) parte da ideia de que a História do Direito é o sucessivo movimento deste nos diversos momentos da sua existência (ou seja: da sua origem, as tendências e a atividade das fontes do Direito, a sua vida na consciência nacional, as formas necessárias para a sua conservação, a divisão em Direito privado e público, etc) e a relação dessas partes, o seu caráter como Direito 
deste povo. Enquanto isso, a História interna possui como seu objeto o repouso, a exemplo da filologia, que para Puchta é importante, porém não seria considerada como a verdadeira História ${ }^{8}$.

Abordando sobre o objeto da Ciência do Direito, Puchta observa que " $a$ Jurisprudência considera o Direito no seu isolamento, ou seja, como Direito especial de um povo, e que lhe transcende os limites apenas quando o Direito deste povo historicamente se conecta aos outros Direitos" (p. 4b). Essa característica de isolamento da Jurisprudência faz com que ela adquira, em certa medida, um caráter nacional, razão pela qual a atividade do jurista na maioria das vezes passa a ser voltada ao Direito de seu povo. No entanto, adverte Puchta que o fato do objeto da Jurisprudência ser o Direito do próprio povo não significa isolar-se e segregar-se de qualquer tipo de comunicação com aquela de outros povos, ou que devesse cercar-se a referida comunicação apenas no campo da Filosofia do Direito. Nesse sentido, baseado no exemplo do contexto da realidade alemã da sua época, ressalta Puchta: "já que não existe apenas nos Direitos de todos os povos que possuem uma origem alemã um elemento comum, que põe um ponto de contato também entre cada uma Jurisprudência, mas (e isso é o mais importante) todas as nações da Europa, e aquelas que se transportam alhures, herdadas pela antiguidade um bem comum, sob o qual se concentra a sua atividade científica, e este o é, porquanto diga respeito à Jurisprudência, o Direito Romano".

Para Puchta, o Direito Romano possui uma dupla importância ${ }^{9}$ : (a) forma um elemento sumamente considerável do Direito presente, ou que valha expressamente, ou que seja incorporado na legislação, que tem sido retratado particularmente no Direito privado; (b) é centro de comunicação entre todas as nações, e da Jurisprudência, sem retirar dela o seu substrato nacional de importância, que transcende os confins de um povo. De tal modo, argumenta Puchta, "a mais nacional de todas as ciências segue a tendência de uma aproximação espiritual de todas as nações, dando a isso um mais seguro fundamento e proíbe, ao mesmo tempo, que aquela tendência não degenere em uma adoção de especialidades estrangeiras, as quais fariam de uma legislação uma obra composta de vários elementos amontoados de forma desordenada" (pp. 5a-5b).

\footnotetext{
${ }^{8}$ Conforme expõe Puchta: "L 'investigazione delle antichità si limita ad uno stato di cose già vieto e trascorso: mentre la storia se si occupa pure del presente, lo concepisce però nel suo sviluppo". (p. 4a)

${ }^{9}$ Para a compreensão da presente colocação deve-se observar o contexto histórico vivido pelo direito alemão à época de Puchta, no qual o Direito Romano Justinianeu era objeto da recepção prática pelo método do chamado "Usus modernus pandectarum" e convivia conjuntamente com disposições do direito nacional.
} 
Assim, um verdadeiro tratamento do Direito Romano pela Ciência do Direito atual seria aquele em que a Jurisprudência "é aquela a qual responda à dupla importância que ele possui, como Direito do povo da qual o recebeu e como Direito geral das nações cíveis" (p. 5b). É nesse sentido, a importância do estudo pela Ciência do Direito dos elementos fundamentais das Instituições Jurídicas ${ }^{10}$.

\section{SOBRE O DESEN VOLVIMENTO DA IDEIA DO DIREITO NA HISTÓRIA}

Segundo expõe Puchta, o desenvolvimento do Direito possui um duplo problema: (a) é necessário que ele se eleve acima de todas as individualidades e diferenças pessoais, não se deixando predominar por isso (para alcançar a sua pureza). Nesse sentido, deverá predominar apenas a personalidade, que é a qualidade que se projeta em todos os povos (e que para Puchta vai ser o princípio fundamental do Direito). (b) é necessário que não se desconheça as variedades individuais - ou seja, que as Instituições do Direito sejam estabelecidas de maneira a responder às existentes necessidades pessoais. Ao primeiro, Puchta denomina de Direito rigoroso e, ao segundo, Direito de equidade.

Segundo Puchta, o conceito de Direito se desenvolveu sucessivamente no tempo, sendo que a origem das nações marcou época na sua formação.

Os Direitos dos povos se diferenciam entre eles em razão da especialidade de cada um também se manifestar sobre o seu Direito, da mesma forma que acontece com sua língua e com seus costumes. Assim, a diversidade do Direito possui uma parte contemporânea (entre aqueles Direitos dos povos existentes em uma mesma época) e uma parte sucessiva. Também com relação a um mesmo povo é observável essa variedade, formando o Direito dele uma história sucessiva ${ }^{11}$.

Assim, um referido desenvolvimento progressivo do Direito permite ver através dele e também reconhecer de porção em porção de cada um dos povos aquele Direito que se seguiu de um povo ao outro. Para Puchta, apenas sucessivamente o conceito do

\footnotetext{
10 "In questo senso gli elementi fondamentali dell'istruzione giuridica, che si à in uso denominare Istituizioni ànno per scopo di servire d'introduzione al diritto romano, qual esse era presso un tal popolo" (p. 5b).

11 "Ogni popolo è un anello della grande catena, che comincia dai secoli, che si perderono nella notte del passato, per unire al termino di essa il diritto di un popolo non circoscrive nella sfera individuale di se stesso: sembra tale a noi, quando ci limitano a considerarlo soltanto il rapporto coi popoli contemporanei. Ma nella sucessione dei popoli esso forma il relaggio della intera umanità” (p. 5b).
} 
Direito alcançou a sua maior clareza e certeza, depositando pouco a pouco as bases que o alicerçavam e o desenvolviam.

\section{SOBRE A ORIGEM E FONTES DO DIREITO, O DIREITO CONSUETUDINÁRIO, $\quad$ O DIREITO LEGISLATIVO, 0 DIREITO CIENTÍFICO, OS MODOS DE RECONHECER O DIREITO E A SUA MUTAÇÃO}

Segundo Puchta, a existência do Direito se funda sobre a Ciência Jurídica dos homens, sendo que esta vem até eles por intermédio de Deus, manifestando-se o Direito como uma ordem divina, a qual se revela ao homem através da sua consciência (p. 7a).

Um pensamento comum supõe a existência de uma consciência comum que lhe seja a fonte, tornando-se um princípio de Direito apenas quando é reconhecido como tal pelo convencimento da referida consciência. Por meio de uma consciência jurídica comum é que os membros de um povo são ligados por um vínculo material espiritual que se estende além do subjetivo. Conforme expõe Puchta, "a consciência que os indivíduos possuem como membros de um povo, a qual é nata com eles e forma a ligação espiritual da sua associação, é a fonte do seu direito das convicções jurídicas que se manifestam e adquirem realidade em cada indivíduo" (p. 7b).

O Direito tem sua existência na consciência humana jurídica e ela permite conhecer mais de perto a consciência nacional. A consciência jurídica é, portanto, a vontade que deriva daquilo que é conforme ao Direito. Mas para que a vontade não venha a criar injustiças, necessário se faz um órgão no qual seja incorporado o Direito e pelo qual se reconheça a sua atuação, o qual será a autoridade do Estado ${ }^{12}$.

Para Puchta, a origem imediata do Direito é invisível (já que é fruto de uma consciência humana), sendo visível o seu produto em si, ou seja, aquele Direito depois que saiu do escuro segredo de onde foi elaborado, nascendo já ligado à sua realidade. Tal fato, na sua origem externa, pode manifestar-se sob três formas: (a) como imediata convenção dos membros da nação, manifestando-se nas suas ações - é o Direito consuetudinário; (b) como lei; (c) como produto de deduções científicas. Os órgãos

\footnotetext{
12 "La volontà di più individui aventi un medesimo dritto intende al certo ad attuare il dritto, ed ad impedire l'ingiustizia: ma la semplice volontà non è a ciò bastante, vi abbisogna un organo, perchè fosse adempiuta. Quest'organo, in cui s'incorpora il dritto, e dal quale riconosce la sua attuazione è l'autorità, colla cui esistenza un popolo addiviene un essere politico, uno stato, senza cui il dritto avrebbe una esistenza soltanto precaria ed imperfetta, e la conscienza comune, sulla quale ha fondamento, sarebbe piuttosto un desidero, anzichè una volontà forte e reale" (p. 8b).
} 
pelos quais o Direito adquire uma forma visível chamam-se fontes do Direito, as quais são: (a) a imediata consciência nacional (costume), (b) a legislação e (c) a Ciência Jurídica.

Segundo Puchta, a manifestação perfeita do Direito consuetudinário ocorre quando os indivíduos operam conforme seu convencimento jurídico, confirmando-o com a prática ${ }^{13}$.

Já o Direito legislativo, enquanto ato de autoridade, manifesta-se quando se faz necessário expressamente estatuir sobre alguns pontos aquilo que pode se considerar como convencimento comum e o governo antecipadamente declara isso como regra geral $^{14}$. Segundo Puchta, uma vez que a lei é feita, a sua validade não poderá mais depender da investigação do seu real acordo com o sentimento universal.

Por sua vez, sobre o Direito científico, Puchta ressalta que "é missão da ciência reconhecer as verdades jurídicas nas suas conexões sistemáticas, como presumível e derivando uma da outra, para perseguir a gênese de cada uma até alcançar o seu princípio, e a partir daí poder derivar dela as últimas conseqüências" (p. 10a). Segundo Puchta, é a partir desse trabalho que "são clareados aqueles princípios que se escondiam no espírito do Direito nacional, os quais não estavam ainda manifestados nem na espontânea convicção ou nos fatos dos indivíduos, nem nas determinações expressadas pelo legislador, e que adquirem uma existência apenas como um produto da dedução científica de uma terceira fonte: o Direito, que se origina a partir dela, é o Direito científico, porque é o produto da atividade do jurista, é o Direito do jurisconsulto" (idem).

Por decorrência lógica de suas ideias, para Puchta o modo de se reconhecer o Direito também vai se dar por meio de uma das três fontes do Direito já referidas anteriormente: a consciência espontânea do povo, a legislação e a ciência.

Quanto à mutação do Direito, observa Puchta que "o escopo, pelo qual o progresso do Direito siga com passos iguais o desenvolvimento histórico de um povo, não irá falir nunca, quando for conservado um livre movimento da atividade das três fontes do Direito" (p. 14a). Desta forma, "se essa trajetória vier a ser turbada, a

\footnotetext{
13 "Questa [manifestazione] avendo a suo fondamento un convincimento comune si repete nei casi simili uniformemente a se stessa sotto le forme di costumi o consuetudini: da ciò denominossi dritto consuetudinário quello che si origina in tal modo" (p. 9a).

14 "Può pretendersi, che il legislatore si faccia realmente l'interpetre dei bisogni comuni nazionali, sia che formoli in legge un principio di dritto già da lungo tempo riconosciuto, o aiuti un concetto che si va formando successivamente, e che è conforme al vero bisogno nacionale" (p. 9b). Cumpre destacar aqui, que Puchta parece ser contrário a função do legislador que cria leis arbitrárias, ou seja, contrário aquele que cria leis por simples ato de legis lar, sem observar as comuns necessidades nacionais.
} 
exemplo de quando se busca enfraquecer a força do convencimento comum, ou da ciência, e remete-se tudo o desenvolvimento ao legislador, será apenas possível evitar um dos males: ou o Direito por meio de bizarras inovações da legislação perde cada uma das suas conexões com a vida histórica de um povo, ou que não responda mais às necessidades do tempo; tanto no primeiro como no segundo caso cessará o acordo do Direito com os outros elementos da civilidade" (idem) ${ }^{15}$.

\section{CONSIDERAÇÕES FINAIS}

Ao longo do presente trabalho, embora de maneira sintética, procurou-se dar atenção direta às ideias de Puchta a respeito da Ciência do Direito, como forma de contribuir com a divulgação do seu pensamento, bem como para provocar questionamentos a respeito daquilo que é divulgado pelos comentadores a respeito da sua obra e contribuições ao Direito.

Restou evidenciado que Puchta adota uma visão contrária à postura racionalista do Direito, uma vez que, no seu entender, o Direito, enquanto fato histórico e organismo social vivo, sempre estará em movimento e sujeito a mudanças ao longo do tempo, possuindo como objeto aquilo que é real. Por outro lado, Puchta, ao salientar a necessidade da Ciência do Direito (e também da Filosofia do Direito) estar ligada à realidade e à prática, coloca em xeque a credibilidade das principais teses divulgadas na atualidade que o apontam como um dos pensadores precursores das teses positivistas ${ }^{16}$.

O positivismo jurídico, a exemplo da construção kelseniana, baseia-se justamente em um pressuposto racionalista que rompeu com a tradição jurídica, enquanto que Puchta, ao contrário daquilo que é divulgado, defende uma postura de

\footnotetext{
15 “Il vero movimento del dritto nella storia dell'umanità sembrerà interrotto solamente a colui, che non si eleva ll'intelligenza dell'intero. Quegli che non si sente membro d'una communità, ma contrapponendovisi come individuo, cerca far valere i suoi isolati interessi, lo crederà stazionario, sia che lo lodi per un tale ristagnamento, finchè venga l'istante in cui gli sia forza destarsi dal suo sogno, o ne muova querele, perchè non risponde ai suoi privati interessi”. (p. 14a)

${ }^{16}$ Karl Laren z é um dos autores que divulgam a tese de ter Puchta preparado o terreno ao "formalis mo jurídico", conforme consta na seguinte passagem de sua "Methodenlehre der Rechtswissenschaft": "Puchta, al haber abandonado la relación, subrayada por Savigny, de las 'reglas jurídicas" con el 'instituto jurídico' a ellas subyacente, en beneficio de la formación abstracta de conceptos, y al haber sustituido por el procedimiento lógico-deductivo de la 'Jurisprudencia de conceptos' todos los otros métodos - y no en último término el de una interpretación y desarrollo del Derecho orientados al fin de la ley y a la conexión de sentido de los institutos jurídicos -, preparó terreno al 'formalismo' jurídico dominante durante más de un siglo, contra el que fue capaz de imponerse mucho tiempo una corriente contraria instaurada por Ihering" (p. 44).
} 
ligação da Filosofia com a realidade, a prática e a tradição histórica ${ }^{17}$. Por outro lado, a proposta de Puchta em sistematizar e organizar cientificamente o Direito através do trabalho do jurista, ao buscar extrair a "pureza" de seus princípios existentes na consciência jurídica humana, não significa a adoção de uma postura positivista ou estática do Direito, uma vez que esse trabalho vai se dar constantemente, acompanhando os movimentos desse organismo vivo.

\section{REFERÊNCIAS BIBLIOGRÁFICAS}

LARENZ, Karl. Metodologia de la Ciencia del Derecho. Tradução de Marcelino Rodríguez Molinero. Barcelona: Ariel, 1994.

PARESCE, Enrico. "Scuola Storica del Diritto", in: Novissimo Digesto Italiano. $3^{\mathrm{a}}$ ed. a cura di Antonio Azara e Ernesto Eula. Tomo XVI. Torino: Unione Tipografico-Editrice Torinese, 1957, pp. 823-827.

PUCHTA, G. F. Corso delle Istituzioni. Tradução e Discurso Preliminar de A. Turchiarulo. Vol. I. Napoli: Tipografia All'Insegna del Diogene, 1854.

THIBAUT, Anton F. J.; SAVIGNY, Friedrich C. von. La Codificación: una controvérsia programática basada em sus obras - "Sobre la necesidad de um Derecho civil general para Alemania" y "De la vocacion de nuestra época para la legislación y la ciência del Derecho". Introdução e compilação de Jacques Stern. Tradução de José Dias Garcia. Madrid: Aguilar, 1970.

WIEACKER, Franz. História do Direito Privado Moderno. 3. ed., trad. portuguesa de A. M. Botelho Hespana, Lisboa: Fundação Calouste Gulbenkian, 2004.

WILHELM, Walter. La Metodologia Jurídica en el Siglo XIX. Tradução de Rolf Bethmann. Madrid: EDERSA, 1980.

\footnotetext{
${ }^{17}$ Nesse sentido, parece ser equivocada a afirmação feita por Walter W ilhelm, a qual tende a conduzir a uma conclusão de que para Puchta o Direito é fruto de uma simples construção racional, cuja ve rdade científica e coerência são aferidas pela análise sistêmica da "vontade da Nação" (p. 71).
} 